\title{
Branquitude e creche: inquietações de um pesquisador branco
}

\section{Whiteness and daycare center: disquietudes of a white researcher}

\author{
Flávio Santiago*
}

\begin{abstract}
RESUMO
O discurso da branquitude construiu o homem branco e adulto como modelo hegemônico da humanidade, representação do legado eurocêntrico. Os pressupostos apresentados neste ensaio trazem inquietações construídas a partir de uma pesquisa etnografia, desenvolvida com crianças de zero a três anos, em uma creche pública do estado de São Paulo, Brasil. Com base nas análises, destaco que a experiência foi marcada pela leitura social do meu corpo, possuidor de traços fenotípicos brancos, os quais foram lidos a partir das imagens racialmente propagadas pela branquitude, bem como se pode observar a conservação de privilégios às crianças brancas pequenininhas.
\end{abstract}

Palavras-chave: Branquitude. Creche. Relações raciais. Etnografia. Sociologia da infância.

\begin{abstract}
The whiteness' speech has built the adult white man as the hegemonic model of humanity, representation of the Eurocentric legacy. The assumptions presented in this essay bring disquietudes built from an ethnographic research developed with children from zero to three years old in a public daycare center of the state of Sao Paulo/Brazil. Based on the analyses, I highlight that the experience was marked by the social readings of my body, carrier of traces phenotypically white, which have been read from the images racially propagated by the whiteness, as well as one may observe the conservation of privileges for the tiny young white children.
\end{abstract}

Keywords: Whiteness. Daycare center. Racial relations. Ethnography. Sociology of childhood.

* Universidade Estadual de Campinas. Programa de Pós-Graduação em Educação. Campinas, São Paulo, Brasil. E-mail: flavio.fravinho@gmail.com. https://orcid.org/0000-0001-7019-2042. 


\title{
Introdução
}

Este ensaio ${ }^{1}$ foi construído a partir de inquietações provenientes da minha trajetória enquanto pedagogo-etnógrafo branco, e os dados que apresento são resultado de uma pesquisa realizada com crianças de zero a três anos de um coletivo infantil em creche pública do estado de São Paulo, Brasil.

Os estudos referentes à branquitude ainda são pouco explorados no contexto acadêmico brasileiro, como afirma Bento (2002, p. 41): "vemos poucas pesquisas que abordem a herança branca da escravidão, e tampouco a interferência da branquitude como uma guardiã de privilégios”.

Ao examinarmos criticamente a branquitude, rompemos com o determinismo biologizante do pensamento racial, colocando em xeque o processo de construção sociocultural dessa forma de segmentação e hierarquização dos sujeitos. Isso propicia pensarmos a raça e o racismo como fenômenos ativos, capazes de determinar fatores econômicos e reguladores das relações sociais (MELLINO, 2015). Evidencia-se como esses elementos são resíduos de uma narração colonial da história pautada pela lógica eurocêntrica de expropriação e opressão de determinados grupos com base na desumanização do outro.

\begin{abstract}
A branquitude incorpora a raça negra enquanto alteridade, unilateralmente, e tende a processar no seu próprio sistema tudo o que for dito para ameaçar a sua situação hegemônica. Mas, pode-se aprender muito sobre a branquitude indagando como as pessoas brancas retratam as pessoas de cor. Enquanto antes se presumia que estudar raça era estudar os negros, existe agora um alerta importante, mas não ainda a conscientização, ao se falar: os brancos, como qualquer pessoa, têm uma raça. A afirmação pode soar óbvia, mas não é. A Raça é um construto social, criado por pessoas e não pela biologia, dentro de um contexto histórico, ou seja, se modifica no tempo (OLIVEIRA, 2007, p. 35).
\end{abstract}

A raça é um elemento forjado historicamente para sustentar privilégios, os quais, quando construímos movimentos para pensar a branquitude, são evidenciados, seja pela reprodução estética contida nas histórias contadas às crianças

1 A pesquisa que dá base a este ensaio foi apoiada financeiramente pela Fundação de Apoio à Pesquisa do Estado de São Paulo (FAPESP)/CAPES, pelo fomento ao processo n ${ }^{\circ} 2015 / 02464-0$ que inclui uma Bolsa Estágio de Pesquisa no Exterior (BEPE), processo n 2016/25474-3. 
pequenininhas, seja pelas ilustrações afixadas na creche, ou pelas posturas assumidas pelas docentes.

Para caminhar na direção de um processo de desconstrução da branquitude, tomo a etnografia como elemento metodológico, pois esta possui a potencialidade de outrar-se ${ }^{2}$, proporcionando movimentos de encontro entre pulsões, sentidos, olhares e escutas que se vão construindo no desdobramento das relações estabelecidas entre o/a pesquisador/a e os sujeitos que constroem seu campo:

Fazer a etnografia é como tentar ler um manuscrito estranho, desbotado, cheio de elipse, incoerências, emendas suspeitas e comentários tendenciosos, escritos não com os sinais convencionais do som, mas com exemplos transitórios de comportamento modelado (GEERTZ, 1978, p. 20).

O que está em jogo não é quantas vezes o sujeito faz uma ação, mas como ele age e os efeitos das suas ações. Com esse modo de percepção do campo, Mauss (2010), em seu livro Manual de etnografia, destaca que o/a pesquisador/a não deve deixar de se atentar a pormenor algum, sendo preciso não só descrever tudo, mas também realizar uma análise em profundidade em que aponte os valores observados em campo a partir de seus referencias, tomando para a compreensão dos dados os elementos culturais. Na construção da pesquisa etnográfica, deve-se necessariamente partir da ideia de culturas como itinerantes; em outras palavras, considerar os processos históricos de deslocamento. Portanto, a cultura deve ser entendida como o efeito da dialética entre local e global, entre o que "reside" e o que está "em viagem" (MELLINO, 2015, n.p).

Dentro desse quadro, o caderno de campo é um elemento fundamental para a reflexão constante das cenas, brincadeiras e falas observadas ao longo da pesquisa de campo. Para além de descrever aquilo que via ou ouvia, pude anotar as minhas dúvidas enquanto homem branco, cisgênero $^{3}$, não heterossexual, de

2 "A encenação do outrar-se compreende a montagem de um cenário enunciativo em que o eu, na sua legítima função de ator no palco, ao invés de apagar a luz sobre o outro, o espectador, incorpora-o para evitar a dispersão característica do discurso e o faz de tal maneira que instala uma tensão permanente, o da in-significância: ponte sobre o abismo que vai do eu ao outro na despedida ou adeus ao eu" (GOMES, 2005, p. 107).

3 Pessoas cisgênero são aquelas designadas com um gênero ao nascer que se identificam com ele. A cisgeneridade é um eixo que constitui a matriz de práticas repetidas a que todas as pessoas são impelidas para performar na produção de coerências e evidências acerca do sexo e também como "um conjunto de dispositivos de poder colonialistas sobre as diversidades corporais e de gênero, sendo tais dispositivos atravessados por outras formas de inferiorização, marginalização e colonização interseccionais" (VERGUEIRO, 2016, p. 72). 
classe operária. Entre algumas dúvidas constantes estavam: como a docente negra interpretaria tal ação? Será que se eu fosse um homem negro as pessoas me perguntariam isso? Por que será que as crianças pequenininhas agem desse modo perto de mim e não se portam do mesmo modo perto de homens negros?

O meu lugar de fala enquanto pesquisador branco é marcado pela historicidade da exploração colonial, que toma como base princípios hierárquicos, demandas sociopolíticas e disputas de poder, legitimando uma supremacia racial que reforça privilégios sociais (HASENBALG, 2005).

Tudo o que nós escrevemos, como aponta Hall (1992, p. 244), "parte de um tempo e de um lugar singulares, de uma história e de uma cultura específicas. Tudo o que dizemos é sempre 'situado', posicionado", a partir dessa prerrogativa. Este ensaio é reflexo também de uma autorreflexão a respeito do meu local de fala enquanto homem branco, uma crítica da branquitude por dentro e de como esse mecanismo está relacionado à masculinidade. $\mathrm{O}$ elemento para pensar essas relações é a desconstrução do meu olhar enquanto sujeito construído socioculturalmente, possuidor de privilégios os quais inúmeras vezes não nos permitem perceber os diferentes processos de estratificação causados pela transformação das diferenças em desigualdades.

Quando destaco os pontos de partida das análises presentes ao longo do texto, não me refiro somente a experiências individuais, mas procuro entender o lugar social de onde eu falo, localizando-me nas redes de poder, as quais interferem diretamente nas experiências do mundo e no acesso à cidadania, bem como no reconhecimento da humanidade das pessoas (RIBEIRO, 2017). No texto procuro também apresentar a interseccionalidade como uma forma de enquadrar as várias interações de raça e gênero no contexto das experiências vivenciadas por crianças de zero a três anos no ambiente de uma creche, articulando a interação do racismo e do patriarcado, e descrevendo a minha localização enquanto homem branco que pesquisa as culturas infantis construídas por meninos e meninas, negros e brancos.

\section{Um pedagogo-etnógrafo branco na creche}

Meu encontro com a creche foi estabelecido por marcas e signos predeterminantes do sujeito que procuro constituir: meu corpo, marcado por traços da masculinidade como barba, cabelo curto e o uso de calças, produzia nas crianças pequenininhas o significante de que eu brincaria com os carrinhos, com as 
bolas ou com os animais em miniatura; brinquedos como panelinhas ou outros utensílios considerados femininos não me eram oferecidos.

Quando pensamos o processo de construção sociocultural das masculinidades, talvez nos venha logo à mente o estereótipo de homem branco, heterossexual, cisgênero, forte, magro; entretanto, é impossível deixar de destacar que esse modelo se assenta em um projeto racial de sociedade, de civilidade, bem como de gênero e sexualidade. No caso específico brasileiro, esse ideal é também marcado pela colonialidade, que é delineada a partir do "desejo de nossas elites pela branquitude imaginada não apenas em termos cromáticos, mas, sobretudo, morais e de poder, da capacidade de autocontrole e domínio dos outros [...]" (MISKOLCI, 2012, p. 121).

O valor da branquitude como status é mais associado aos homens, enquanto a brancura da cor de pele e a ideia de beleza branca são mais ligadas ao feminino, e têm mais preciosidade para as mulheres brancas do que para os homens brancos. Como aponta Schucman (2018), os estudos acerca da branquitude paulista demonstram que há uma fronteira interna de gênero entre os brancos que diferencia o valor da branquitude para homens e mulheres, marcando fronteiras externas relativas a sexualidade, matrimônio e afetividade. Nesse sentido, como aponta Brah (2006), isso se constrói de maneira diferente conforme a localização nas relações de poder; não existimos simplesmente como mulheres ou homens, mas como categorias diferenciadas, tais como mulheres de classe trabalhadora, mulheres negras, homens camponeses. Cada descrição representa uma condição social específica, a partir da qual são forjadas vidas.

A percepção do que representa a masculinidade de um homem branco era tão forte que, um dia, brincando com as crianças pequenininhas, um menino negro pequenininho me fez repensar meu papel enquanto pesquisador:

Observava as crianças pequeninhas brincando com um fogãozinho, resolvo me aproximar e pergunto:

- Nossa, que legal, o que você tá cozinhando?

No mesmo instante, o menino negro pequenininho para de brincar e me responde:

- Tio, eu não brinco com fogão, é coisa de menina! Você sabe, é menino, sabe disso!

- Ah, eu não acho que é só menina que brinca de cozinhar, eu também gosto!

- Eu não gosto! Isso é brincadeira de menina!

A docente me chama, vou ao encontro dela; ao olhar novamente para o fogão, observo que o menino negro pequenininho, que me disse que não gostava de brincar com o fogão, volta a brincar nele, interagindo com outros colegas (Diário de campo, abril de 2016). 
Daquele momento em diante, comecei a observar que, quando me aproximava das brincadeiras ditas não masculinas, os meninos pequenininhos, fossem negros, fossem brancos, paravam de brincar, dizendo para mim: "tio, eu não estava brincando". Essa percepção só passou a ser quebrada no decorrer da minha permanência na creche, após os meninos pequenininhos terem me visto brincando com bonecas e carrinhos, e perceberem que não me importava que eles também brincassem com esses brinquedos. Somente então eles deixaram de parar de brincar de boneca quando me aproximava.

Com base nos inúmeros momentos vivenciados no campo e na literatura da área de gênero e relações raciais, posso afirmar que a minha figura de homem branco transmitia às crianças pequenininhas a ideia de controle, vigilância. Não que eu agisse dessa forma, mas a representação da masculinidade branca as conduzia a essa percepção. "Na ordem patriarcal de gênero, o branco encontra vantagem, [...] o poder é macho, branco e, de preferência, heterossexual" (SAFFIOTI, 2015, p. 33).

A branquitude, como aponta Laborne (2014, p. 53), "seria um lugar, um status ocupado pelas pessoas brancas e herdado de relações sociais e fundamentalmente raciais do passado". Caracteriza-se pela colonialidade nas sociedades que constroem um lugar de privilégios materiais e simbólicos, criando fronteiras externas entre brancos e negros e distinções internas que hierarquizam os brancos através de outros marcadores sociais de diferença, como classe social, gênero, origem, regionalidade e fenótipo (SCHUCMAN, 2018).

A partir dessa prerrogativa, comecei a pensar sobre quem eram os homens da creche e verifiquei que eram poucos, todos brancos, que representavam postos de vigilância: o porteiro ${ }^{4}$, os zeladores e os coordenadores das empresas terceirizadas que frequentavam a creche algumas vezes. Dentro daquele contexto, as únicas pessoas negras eram mulheres, que ocupavam os cargos de auxiliares de limpeza, docentes, cozinheiras, sendo os locais entendidos como de controle, a exemplo da saída e entrada da creche, gerenciados por homens brancos. A branquitude na nossa sociedade é marcada por um processo de hierarquização racista que significa poder; "a identidade racial branca é um lugar de privilégios simbólicos" (CARDOSO, 2011, p. 81).

As crianças pequenininhas, desde o momento em que entravam na creche, observavam que os homens brancos controlavam a sua entrada e saída, e organizavam os brinquedos com os quais brincavam; assim, a associação da minha figura como controlador também era possível.

4 No meio do ano de 2016, a instituição ficou somente com uma funcionária na portaria: uma mulher negra. 
[...] ideologias racistas não são recebidas de forma passiva, mas são usadas de maneira a ajudar as próprias crianças a compreender suas condições materiais e culturais [...] na vida das crianças, o racismo é uma posição sujeita a condições, determinante na medida em que pode ser usado para dar sentido ao próprio mundo (BASTIANONI; VILLANO, 2013, p. 240, tradução nossa).

A identidade racial branca, como destacam Cardoso e Dias (2017), não é homogênea; a branquitude precisa ser considerada como a posição ocupada pelo sujeito, surgida na confluência de eventos históricos e políticos determináveis. Ser branco tem distintos lugares, no entanto é a branquitude que modela as estruturas hierárquicas.

$\mathrm{Na}$ América, a ideia de raça foi uma maneira de outorgar legitimidade às relações de dominação impostas na conquista. A posterior constituição da Europa como nova identidade depois da América e a expansão do colonialismo europeu ao resto do mundo conduzem à elaboração da perspectiva eurocêntrica [branca] do conhecimento e com ela à elaboração teórica da ideia de raça como naturalização dessas relações coloniais de dominação entre europeus e não-europeus. Historicamente, isso significou uma nova maneira de legitimar as já antigas ideias e práticas de relações de superioridade/inferioridade entre dominantes e dominados (QUIJANO, 2005, p. 118).

As diferenças foram utilizadas para justificar a hierarquização social. Com esse quadro, as crianças pequenininhas me fizeram problematizar e pensar o meu local de pesquisador e homem branco, o que meu corpo representava dentro do contexto socio-histórico, levando-me à percepção de que as nossas localizações enquanto sujeitos na estrutura social possibilitam a construção de interpretações e a condução de pesquisas de modos distintos, assim como diferentes relações com o campo de pesquisa. A percepção desse entrecruzamento está diretamente relacionada ao reconhecimento do lugar de fala, como aponta Sovik (2017); as questões de imagem e autoimagem foram construídas no contexto brasileiro para se pensar a elaboração de aportes críticos a respeito da branquitude.

É importante destacar que, no primeiro dia da turma na creche, as docentes das salas me apresentaram para as crianças pequenininhas como um pesquisador que acompanharia as atividades desenvolvidas durante todo o ano de 2016. Talvez as crianças não soubessem o que é ser um pesquisador em 
nível de doutoramento, mas sabiam o que representava a figura de um adulto naquele contexto.

No decorrer dos dias, depois de pedir permissão para participar das brincadeiras, aproximei-me das rodas de conversa e consegui romper com algumas fronteiras que me separam dos meninos pequeninhos e das meninas pequeninhas; as crianças pequenininhas tiveram a percepção de mim enquanto adulto que não julgava aquilo com o que elas brincavam; pude brincar com as bonecas e na caixa de areia, e até subir junto com elas os morros da creche sem impedimentos ou qualquer julgamento que poderia repreendê-las a partir do que seria ser um menino pequenininho ou uma menina pequenininha. De acordo com o pensamento de Corsaro (2005), pode-se afirmar que me tornei um adulto atípico, aquele que participa das atividades com pouco ou nenhum entrave.

Por meio da participação coletiva nas atividades das crianças, fui me tornando membro das suas relações sociais. A ideia inicial, construída com base no imaginário social a respeito do que simbolizava um homem branco, foi redesenhando-se a partir das interpretações que as meninas pequenininhas e os meninos pequenininhos construíam a partir de nossas interações. As relações entre as crianças são construídas coletivamente por suas participações ativas nas relações sociais e culturais, uma ideia claramente relacionada à noção de reprodução interpretativa (CORSARO, 2011).

Como destaca Corsaro (2011), no momento em que as crianças constroem uma relação com o/a outro/a, elaboram atividades compartilhadas em conjunto em uma área específica e protegida contra "invasões alheias". Assim, as crianças criativamente se apropriam do conhecimento social que lhes foi apresentado pela rotina adulta e o ampliam. As crianças também protegem seus espaços interativos e, a partir desse processo, percebem que podem ser protagonistas das próprias atividades, negociando quem irá participar delas; a partir desse movimento, compreendem suas identidades sociais, que estão sendo construídas.

Como de costume, todos os dias eu chegava à creche e me sentava em um canto no fundo da sala da turma que acompanhava, conversando/brincando com as crianças pequenininhas. Minha estratégia era tentar estabelecer certa distância em relação à docente, procurando criar uma imagem que não me associasse à função de docente dentro da creche. Para as docentes, por sua vez, ter por perto um adulto era no mínimo uma situação embaraçosa. Por isso, elas constantemente tentavam me envolver nas tarefas diárias. Às vezes, não era fácil recusar certos pedidos, mas eu os recusava; sempre que possível, elas buscavam entender a minha percepção a respeito da atividade que estava acontecendo: "Hoje temos que fazer a parte pedagógica!"; "O que você acha da atividade que realizamos?"; "Nossa, você viu?"; "E como anda sua pesquisa, já conseguiu os dados?"; "Eu tô ajudando na pesquisa?". 
Esses questionamentos muitas vezes esperavam uma resposta, talvez uma aprovação, ou eram uma forma de me dizer que eu estava sendo acolhido e que de algum modo elas gostariam de contribuir com a pesquisa. Entretanto, ao longo dos meses, fui demonstrando, por meio de atitudes, que não estava na creche para fazer julgamento moral do trabalho desenvolvido com as crianças pequenininhas, nem mesmo propor atividades; estava ali para participar das interações das/os meninas/os pequenininhas/os, negras/os e não negras/os.

As docentes não me questionavam somente quanto a suas posturas pedagógicas, como também em relação ao meu papel político enquanto pesquisador e homem branco. Durante uma entrevista, uma docente verbalizou explicitamente essa inquietação:

Nós fizemos uma formação esses dias na Fazenda Roseira com uma negra de verdade, isso é... também é uma formação de verdade porque é uma negra que está falando. Ela faz o mestrado. Ela é negra, ela estava lá. Porque aqui, por exemplo, vem o cidadão aqui falar de negro, o cidadão branco, gente? Cabelo lisérrimo, daquelas barbas, aqueles meninos socialistas bonitos. Entendeu? Não que não seja válida a formação que ele tem, o estudo que ele fez, mas nada como uma pessoa da própria cor falar (informação verbal, Harbuu, docente negra, entrevista concedida em 2016).

Diante desse questionamento, é importante destacar que não tomo a autoridade de falar dos sujeitos negros/as nem das crianças pequenininhas, tampouco desconsidero as experiências vivenciadas por eles/as. Contudo, as dimensões do processo de racialização, das relações de gênero e adultocêntricas envolvem todas as relações sociais, influenciando diretamente a construção da vida. O meu papel político enquanto homem branco é "criar espaço e condições de autorrepresentação e de questionar os limites representacionais, bem como o seu próprio lugar de enunciação e sua cumplicidade no trabalho intelectual" (SPIVAK, 2010, p. 15).

A cada encontro com o campo, fui me deixando ser afetado pelos questionamentos e por todos os elementos interculturais que as crianças pequenininhas e as docentes me colocavam, bem como repensando meus privilégios de homem branco. É importante frisar que as relações pautadas na branquitude não são mera característica das relações sociais; sua força depende sobretudo das hierarquias, do sistema de privilégios e da violência material das quais são veículo, e não se constituem simplesmente como um estereótipo. As sociedades racistas se formam precisamente a partir da proliferação de espaços e nichos 
altamente hierarquizados e racializados que, de alguma forma, transcendem a vontade e a subjetividade de indivíduos e grupos (CURCIO; MELLINO, 2012).

Em nossa sociedade brasileira, as pessoas de tez mais escura sofrem mais com os efeitos do racismo; a perversidade estabelecida pela hierarquização pautada na branquitude, que força o desenraizamento das origens culturais africanas e afro-brasileiras, cria processos de "mutilação subjetiva" ligados ao reconhecimento e à construção do pertencimento racial da população negra com seus pares (FANON, 2008; FERNANDES, 2007).

Estes fatos, assim como olhares, palavras, gestos, cotidianamente são dirigidos a pessoas negras, indigenas, pessoas ciganas, a pessoas empobrecidas. E fazem com que cada pessoa, e notadamente as crianças, se deem conta de que a sociedade lhes reserva certos lugares, oportunidades, direitos e as exclui de outros. Então haveria um lugar, haveria uma humanidade que não pertence a todos. Preconceitos sobre os quais se constrói a nação brasileira continuam cultivando sentimentos e ideias de que para pertencer à humanidade é preciso ser descendente de europeus ou é preciso ser branco. Quem for branco ou quanto mais branco, mais humano seria (informação verbal, Silva, 2015) .

Dentro desse contexto, o corpo em si não tem poder nem valor; os signos criados sobre ele resultam em um processo de abstração com base no desejo exterior (MBEMBE, 2014). Os negros e as negras passam a ser aqueles que não correspondem às regras impostas (ou que as infringem). Um dia, quando fui beber água no refeitório da creche, me deparei com algumas imagens coladas próximas à torneira (FIGURAS 1 e 2). As imagens foram confeccionas pela Prefeitura Municipal para uma campanha educativa voltada à redução e ao controle do desperdício de água, bem como para a construção de bons hábitos de higiene na utilização dos bebedouros.

5 Fala de Petronilha Beatriz Gonçalves e Silva na Mesa-redonda "Entre os tratados coloniais e a emancipação humana: a luta pelo reconhecimento das diferenças" do $2^{\circ}$ Seminário Internacional sobre Infâncias e Pós-Colonialismo, Campinas, 2015. 
FIGURAS 1 E 2 - INFORMATIVO BEBEDOUROS

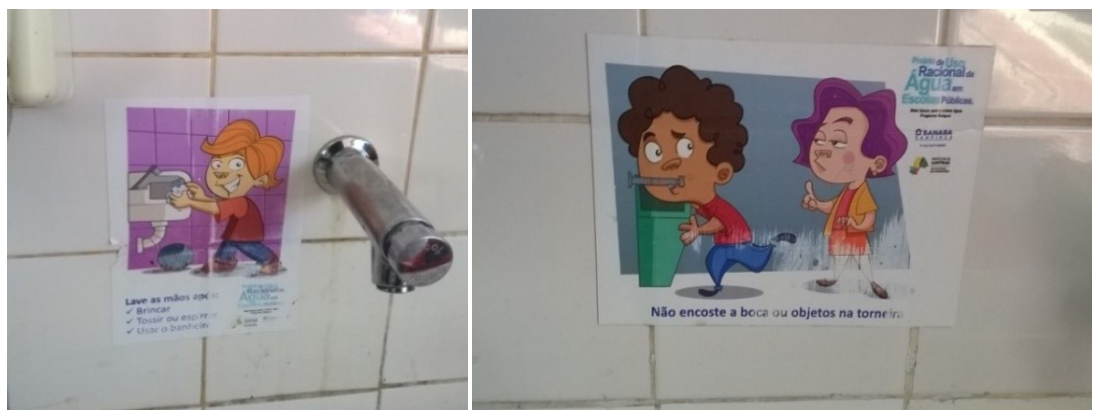

FONTE: Registros do autor.

A proposta educativa para o não desperdício no consumo da água é uma iniciativa interessante; contudo, por que somente o menino negro é representado como o arteiro e aquele que desperdiça? E por que o menino branco é representado como o comportado? Será que essas imagens não educam também para as relações étnico-raciais?

As representações afixadas nas paredes da instituição de educação infantil são expressões culturais localizadas e constroem espaços de significados que expressam as relações sociais e seus contextos históricos. A produção dos espaços, como aponta Santos (1988), é resultado da ação de homens, mulheres e crianças sobre o próprio espaço, por meio dos objetos naturais e artificiais. Cada tipo de paisagem é a reprodução de níveis diferentes de forças produtivas, materiais e imateriais, das quais também faz parte o conhecimento.

Nesse sentido, podemos conceber as imagens afixadas acima dos bebedouros como materialização socio-histórica de processos hierárquicos forjados no contexto brasileiro que expressam um passado de construções simbólicas que ligam os negros à malandragem e à má conduta, nas intersecções entre a racialização e as relações de gênero. Diante desse fenômeno, é importante destacar o ranço colonial que se articula a partir do legado patriarcal de modelo senhorial construído durante o período escravocrata brasileiro, o qual legitimou o estabelecimento de relações de dominação cultural eurocêntrica ao longo dos séculos de escravidão. Também justificou a expropriação colonial racializada e racista em que vivemos (WERNECK, 2010), marcando diferentemente homens e mulheres com base no pertencimento racial.

É fundamental enfatizar que o racismo e as teorias que o justificam não caíram do céu; possuem uma historicidade que 
[...] nasce quando se faz intervir características biológicas como justificativa de tal ou tal comportamento. É justamente o estabelecimento da relação intrínseca entre caracteres biológicos e qualidades morais, psicológicas, intelectuais e culturais que desemboca na hierarquização das chamadas raças em superiores e inferiores (MUNANGA, 2004, p. 25).

O racismo foi criado para legitimar os fenômenos ideológicos e políticosociais, constituindo-se como um fenômeno ocidental e moderno (TAGUIEFF, 1999). Essa percepção ideológica ainda ressoa cotidianamente em nossa sociedade, podendo ser constatada corriqueiramente nas observações construídas a respeito dos meninos pequenininhos negros. Em entrevistas concedidas pelas docentes da creche pesquisada, pude observar que o imaginário racializado do que constitui a masculinidade negra recai no estereótipo do sujeito malandro, bagunceiro, arteiro, reforçando todos os padrões normativos presentes no legado histórico racista fundamentado em atributos físicos. Nas entrevistas, em inúmeros momentos elas destacaram que essa forma de percepção ainda é muito presente dentro da creche, apontando também que alguns comportamentos dos meninos negros pequenininhos advêm do seu contexto social:

[...] os meninos negros são mais repreendidos, eles são mais... tem um pouco dessa concepção assim, tem que segurar, porque isso... vai dar o quê? Aliás, eu já ouvi isso, né? Eu estou reproduzindo uma fala de uma educadora. Se eu não seguro, vai virar o quê? Bandido, marginal, violento. Então, ali a questão da cor da pele, da negritude, da afrodescendência, a possibilidade de virar marginal, eu já prefiro pensar que vai virar um presidente da república, mas tem gente infelizmente que segura mais... (informação verbal, Adeola, docente negra, entrevista concedida em 2016).

Eu acho que os meninos negros são mais agressivos, eles batem... aí de novo penso na questão social deles, do dinheiro, porque a gente sabe que existe violência doméstica, e nas classes mais baixas isso é mais explícito... você vivencia isso e retrata depois (informação verbal, Harbuu, docente negra, entrevista concedida em 2016).

O estereótipo da malandragem que adorna as percepções a respeito dos meninos negros pequenininhos não está recheado do glamour cantado em muitos sambas nacionais. Ele carrega o fardo cultural de um processo histórico pautado na lógica da colonialidade, marcado pelos princípios de civilidade impostos 
pela branquitude e pela desigualdade de classe presentes em nossa sociedade capitalista. "O preto é um brinquedo nas mãos dos brancos" (FANON, 2008, p. 126). O imaginário que recai nos meninos negros pequenininhos ressoa as mais perversas estruturas do racismo.

$\mathrm{O}$ estereótipo do menino negro pequenininho como o malandro agrega características que o adornam como instável, esperto, erótico e, por vezes, violento. Essa percepção, assim como a da mulata, vem acompanhada de significados ambíguos, reafirmando os estereótipos criados a respeito dos homens negros e reforçando uma percepção do que seria a masculinidade negra da classe trabalhadora.

Os meninos negros pequenininhos são repreendidos com maior frequência. Não estamos somente procurando construir um bom comportamento diante dos combinados e das normas predefinidas entre os/as membros/as da turma, mas também resgatando um passado colonial em que havia a necessidade fundamental de reprimir com violência o homem negro para que ele não ousasse transpor as fronteiras da hierarquização escravocrata, expondo o medo latente de transgressões da população negra ao regime da colonialidade. A classificação e as tipificações, como apontam Alietti e Padovan (2000), são usadas para suspender a dúvida a respeito das peculiaridades e incertezas que afligem a vida cotidiana. Portanto, numa situação de hierarquização entre grupos, os argumentos não dizem respeito em momento algum a aspectos biológicos, mas a questões socioculturais.

A exemplo desse processo, Harbuu, docente negra, apresenta que muitas vezes as crianças brancas têm privilégios em relação às outras:

Loirinho, lourinha, do olho claro tem tratamento diferenciado. Aqui é nítido. "Você vai dar banho?" "Por que ela tem que tomar banho?" Ela não precisa tomar banho". Algum tempo depois, a criança sai banhada, com o cabelo arrumado. Ai eu pergunto: "Por que deu banho nela? Agora dá banho naquela dali, ó". Porque só a criança loira tem esse privilégio. "Essa criança não precisa tomar banho aqui na escola. Ela toma banho todo dia na casa dela. Agora tem outro aqui, em sua maioria negros, que tava precisando tomar um banho. Por que você não deu? Você só deu naquela criança loirinha". É assim... é... o negócio é... não é velado... é escancarado o negócio (informação verbal, Harbuu, docente negra, entrevista concedida em 2016) ${ }^{6}$.

6 É importante destacar que todos os nomes foram substituídos, seguindo os padrões éticos estabelecidos pelo Comitê de Ética da Unicamp. A pesquisa que dá base a este ensaio foi aprovada pelo mesmo comitê de ética, tendo como CAAE o número: 50873015.0.0000.5404. 
Esse dado ressoa em pesquisas já realizadas no campo de relações raciais e educação (CAVALLEIRO, 2003; DIAS, 1997, 2007; OLIVEIRA, 2004; ROSEMBERG, 1996; SOUZA, 2012; TRINIDAD, 2011). A respeito dessa temática, durante a sua entrevista, a docente destacou outros elementos:

[...] as crianças que são mais bonitinhas, mais loirinhas, né? As pessoas tratam melhor mesmo. Você não vê muita gente fazendo gracinha com criança negra, de fato. Você vê mais com criança branca, isso desde a entrada da guarda até lá. [...] As pessoas brancas ou ditas brancas brincam mais com crianças brancas. Pega mais no colo, dá muito mais carinho. Nesse processo, a criança negra vai se retraindo, vai ficando mais tímida, porque pra mim ela percebe. Desde bebê. Desde bebê percebe. Porque se uma pessoa vai lá, por exemplo, vai lá.... "Eu gosto daquela menininha branquinha, vou lá todo dia, faço carinho, pego no colo, brinco e a outra não, a outra não, a outra não...", é impossivel. Ela percebe, não tem como não perceber, até porque o negócio é muito escancarado. Eu acho. $O$ acolhimento, no geral, na minha opinião, ele é ruim para todas as crianças. Ele é ruim... É, é um processo ruim desde o começo pra todo mundo. Ele é muito ruim. Eaí, éóbvio que volto a dizer, se é uma criança bonitinha, branquinha, cheirosinha, ela vai ter mais carinho, ela vai ser muito melhor acolhida, enquanto o outro... ai o processo dele vai demorar mais ainda. Ai o sofrimento é maior ainda (informação verbal, Harbuu, docente negra, entrevista concedida em 2016).

Ao encontro da fala de Harbuu, Cavalleiro (2003) apontou em sua pesquisa que as docentes da educação infantil afirmam a existência de racismo e consideram em muitos momentos normal o tratamento desigual dispensado às crianças, reforçando o ideário da existência de uma democracia racial no Brasil.

Como aponta Fernandes (2008), as circunstâncias histórico-sociais fizeram com que o mito da "democracia racial" criado fosse manipulado como conexão dinâmica dos mecanismos societários da defesa dissimulada de atitudes, comportamentos e ideais aristocráticos dos brancos. Essa dinâmica reforça os padrões de exclusão, como aponta a pesquisadora Cavalleiro (2003) em seu livro Do silêncio do lar ao silêncio escolar: racismo - preconceito e discriminação na educação infantil, com relatos de docentes que acreditam que essas formas de estabelecimento das relações não interferem no cotidiano da educação infantil, pois, para elas, as crianças não percebem a forma desigual com a qual são tratadas. 
Então haveria um lugar, uma humanidade que não pertence a todos. Preconceitos sobre os quais se constrói a nação brasileira continuam cultivando sentimentos e ideias de que para pertencer à humanidade é preciso ser descendente de europeus ou é preciso ser branco (informação verbal, Silva, 2015) ${ }^{7}$.

As hierarquias sociais resultantes da configuração racial no Brasil privilegiam as crianças brancas pequenininhas em posições de protagonismo em festas, danças e teatros construídos no interior das creches; nesse contexto, as crianças negras pequenininhas normalmente não são, por exemplo, o casal de noivos da festa junina da instituição educativa.

O imaginário da branquitude a respeito das relações de gênero está presente em todos os espaços, inclusive no cotidiano da creche. Nesse processo, o branco aparece como modelo universal de humanidade, alvo da inveja e do desejo dos outros grupos raciais, encarados como não tão humanos. A branquitude foi inventada e mantida pela elite branca brasileira ${ }^{8}$, no entanto, é apontada por essa mesma elite como um problema do negro brasileiro, construindo um imaginário negativo a respeito deste que solapa sua identidade racial, danifica sua autoestima, culpa-o pela discriminação que sofre e, por fim, justifica as desigualdades raciais (BENTO, 2002).

No tocante à elite branca brasileira, entre as diferentes ferramentas sociohistóricas utilizadas para manter seus privilégios, temos o projeto elaborado pela Comissão Brasileira de Eugenia, que possibilitou mudanças na Constituição de 1934 promulgando o artigo 138, que determinava a responsabilidade da União, dos estados e dos municípios, nos termos da respectiva lei, no estímulo à educação eugênica, condicionando a educação como prática de melhoramento racial (ROCHA, 2018).

Verifica-se que ressoam até hoje esses princípios; como exemplos desse processo temos as histórias contadas para as crianças, que são, em sua maioria, ainda relacionadas a contos de fadas eurocêntricos cujas princesas esperam um príncipe lhes prover a vida - símbolo clássico do patriarcado. Histórias como

7 Fala de Petronilha Beatriz Gonçalves e Silva na Mesa-redonda "Entre os tratados coloniais e a emancipação humana: a luta pelo reconhecimento das diferenças" do $2^{\circ}$ Seminário Internacional sobre Infâncias e Pós-Colonialismo, Campinas, 2015.

8 A imagem de um Brasil branco se caracterizou pelo incentivo à entrada de imigrantes, privilegiando aqueles de origem europeia tendo em vista o "branqueamento da raça" (SEYFERT, 1987). 
as das rainhas candaces ${ }^{9}$, da rainha guerreira Nzinga $^{10}$ e de Dandara ${ }^{11}$, que, além de reinar, eram guerreiras e comandavam exércitos nas guerras, dificilmente são contadas às crianças. O que observamos é um reforço dos modelos da branquitude que legitimam as características físicas e os comportamentos esperados para meninos e meninas, às vezes, ideologicamente, nos pequenos gestos e práticas do dia a dia na educação infantil (FINCO, 2004).

Farias (2016) apresenta, em sua dissertação de mestrado, um exemplo clássico da perversidade do branqueamento que assola as relações sociais, descrevendo que Nanã, uma menina de cinco anos, a desenha loira (mesmo ela não sendo) e justifica que "loira você fica muito mais bonita". Nanã quis presentear a pesquisadora com as características da branquitude.

Diante desses dados, questionava-me quanto ao acolhimento das crianças negras pequenininhas pela creche; e, durante a entrevista com a docente Zarina, pensamos conjuntamente um pouco a respeito desse processo e de suas intersecções com o racismo estrutural:

Pesquisador: Você acha que as crianças negras têm dificuldade no acolhimento na creche?

Zarina: Cada caso é um caso. Então, vamos pensar lá. A Núbia: ela é uma criança negra, ela é uma criança que fica nesse movimento de observar muito e tem essa barreira na construção dos vínculos afetivos, eu acho, mas eu também trabalhei com o Thabo, dei aula para o Thabo, que é o irmão dela, que é a Núbia de cabelo comprido, né? Enrolado.

Pesquisador: Os dois são negros?

Zarina: Os dois são negros. A Núbia era igual. É, vamos pensando, você está me provocando e a gente está pensando. E aí, vamos pensar, a Núbia, né? A Sharifa acho que foi muito tranquilo, que é uma menina negra, do cabelo liso, né? Mas os meninos, por exemplo, vamos falar dos meninos; $o$ Talib que eu fiquei extremamente chateada com a família, porque mandou

9 Corajosas guerreiras, as rainhas candaces exerceram funções políticas, sociais e culturais, assumindo a totalidade do poder no Império de Cuxe (ou Reino de Kush). Mais informações em: CANDACES: a história das rainhas negras de Kush. Princesas de Sabá [Blog]. 21 out. 2015. Disponível em: https://princesadesaba.wordpress.com/2015/10/21/candaces-a-historia-das-rainhasnegras-de-cuxe/. Acesso em: 03 abr. 2017.

10 Mais informações em: A RAINHA Guerreira Nzinga. Geledés. 30 maio 2009. Disponível em: http://www.geledes.org.br/a-rainha-guerreira-nzinga/\#gs.koP7HPE. Acesso em: 03 abr. 2017.

11 Mais informações em: DESCRITA como heroína, Dandara, mulher de Zumbi, tem biografia cercada de incertezas. Instituto Humanitas Unisinos. 19 nov. 2014. Disponível em: http:// www.ihu.unisinos.br/noticias/537524-descrita-como-heroina-dandara-mulher-de-zumbi-tembiografia-cercada-de-incertezas. Acesso em: 03 abr. 2017. 
aquele bilhete superjoinha, dizendo que achava uma pena que a gente não estava querendo acolher o filho, que não estava querendo acolhê-lo, eu fiquei muito chateada; eu acho que o Talib foi uma das crianças que eu mais pelejei para acolher, e eu acho que eu acolhi bastante, assim, de respeitar que era um momento dolorido, o Talib era a primeira vez que ele estava indo para a escola, a mãe estava em casa, o pai não sei se trabalhava ou não, mas enfim, estava nesse processo, eu acho que os pais trabalhavam, os pais são negros, o Talib é negro, ele ainda mamava no peito. Isso é uma coisa que me angustia muito, as meninas sempre dizem "ah, é muito complicado a criança que mama no peito vir para a escola", mas a gente está criando um grupo na escola que chama Maternidade de Mãos Dadas, que incentiva o aleitamento inclusive na escola. Eu, de fato, eu ainda não tenho uma ideia, não sei se a criança que mama no peito ela tem mais dificuldade de ficar na escola do que aquela que não mama, eu não sei (informação verbal, Zarina, docente branca, entrevista concedida em 2016).

As instituições de educação infantil no Brasil inúmeras vezes constituem um lugar hostil para as crianças negras pequenininhas, não possuindo artefatos culturais que contribuam para seu acolhimento, bem como são marcadas pelo racismo institucional presente em nossa sociedade. Paralelamente a esse processo, muitos dos aspectos relativos ao acolhimento das culturas africana e afro-brasileira, e a desconstrução do racismo institucional, não se fazem presentes no cotidiano das instituições.

Esse processo é reflexo do que podemos denominar racismo estrutural, que exige, em primeiro lugar, a criação e recriação de um imaginário social em que determinadas características ou práticas culturais sejam desvalorizadas ou invisibilizadas para que a desigualdade e a violência apareçam de forma "estilizada", e possam estar integradas à "normalidade" da vida social, tornando os sujeitos apáticos e indiferentes ao modo como determinados grupos raciais são invisibilizados (ALMEIDA, 2017). Na lógica colonial, a história é contada a partir de uma única ótica, a qual contribui para legitimar as estruturas patriarcais e racistas que sustentam as desigualdades.

Evidencia-se, assim, o epistemicídio ${ }^{12}$ do conhecimento negro em toda a história do Brasil, reforçando um sistema complexo de estruturação de diferen-

12 O conceito de epistemicídio - a morte de "conhecimentos alternativos" - foi extraído das reflexões de Boaventura de Souza Santos (1995), para qual constitui num dos instrumentos mais eficazes e duradouros da dominação étnica/racial, pela negação que empreende da legitimidade das formas de conhecimento, desconhecimento produzido pelos grupos dominados e, consequentemente, de seus membros enquanto sujeitos de conhecimento. 
tes níveis de poder e privilégios, o qual é "constituído como um instrumento operacional para a consolidação das hierarquias raciais" (CARNEIRO, 2005, p. 33). Tudo isso diz respeito ao reconhecimento da nossa igualdade enquanto seres humanos e sujeitos de direitos, e da nossa diferença enquanto sujeitos singulares em gênero, raça, idade, nível socioeconômico e tantos outros (GOMES, 2012, p. 105). Diante desse dado, podemos afirmar que a instituição investigada apresenta perspectiva eurocêntrica, pautada em aspectos da colonialidade do ser e do saber (QUIJANO, 2014). Esses elementos podem ser observados nas falas de algumas docentes:

Você sabe que a nossa escola está parecendo um hospital, né? [...] nas paredes da escola também não tem nada que... [...] houve um comentário dentro de um grupo na verdade de WhatsApp, houve um comentário que não podia rezar tal, tal, tal e que não podia trazer nada da cultura negra porque era tudo da macumba. Ah, ai eu fiquei um bicho, eu estava afastada, eu falei "Gente, nós vamos precisar estudar. Porque a macumba, a cultura africana não é só a religiosidade, embora as evangélicas cantam as coisas da igreja e ninguém está discutindo isso. Então, quando é para as questões africanas, a escola é laica. Quando é para as questões evangélicas a escola não é laica? Então a gente precisa..." e aí colocaram um vídeo de uma mulher evangélica, nem me lembro, é o grupo... uma das professoras evangélicas colocou esse vídeo e ela descendo a lenha que essa questão de etnia tinha a ver com macumba, com religiosidade, e ai eu falei "Vamos ter que estudar" e ai a escola abraçou essa ideia. Então, graças a essa polêmica que aconteceu por conta da religiosidade, e se a gente discutisse? Eu sinto falta, por exemplo, novembro tem o Dia da Consciência Negra, poderíamos, não precisa ser novembro, o pessoal confunde, ah, vamos trabalhar em data comemorativa, trabalhe qual tempo for, trabalhe a cultura do indio, trabalhe a cultura da... Africa, precisa de mais trabalho, é legislação inclusive, a legislação exige. Embora depois da Escola Sem Partido acho que vão tirar tudo, mas, enfim, é a legislação, a gente teria que trabalhar, a gente teria que trazer que $90 \%, 80 \%$ da população brasileira é afrodescendente. E teríamos que ter a Africa representada nas paredes da escola, nas roupas das mulheres, levar a nossa escola para passear nesses espaços como a Fazenda da Roseira, por exemplo, que é um espaço que acolhe as pessoas. Eu fiquei feliz de ver que pelo menos as educadoras já começaram a ir nos espaços de cultura negra... tanto é que na Semana da Família nossa teve aquele espaço do cabelo, do turbante etc. e tal, "Olha o meu cabelo como é lindo" etc., por conta dessa discussão que a gente está fazendo, então nós já melhoramos. Só que eu acho que essa discussão da formação, eu penso que ela tem que vir para a prática, eu tenho que 
trabalhar isso com as minhas crianças da sala, eu tenho que oferecer mais coisas da cultura africana, mais coisas da cultura dos indigenas, independentemente de leis, não importa, se eu vou discutir em junho ou abril, eu não estou preocupada com data comemorativa, mas eu estou preocupada que essa formação que a gente fez e agora graças a Deus as pessoas descobriram que a África não é só religião, né? Que a África é muito mais que isso e nós temos muito... ontem veio um rapaz falar sobre capoeira. A capoeira, por muito tempo, ela foi criminalizada aqui no país, nós não descobrimos ainda a capoeira, a capoeira lá fora é... você vai na Dinamarca, em Paris, outros lugares, nossa, o pessoal fala muito bem da capoeira, dança capoeira, brinca capoeira, então, por que nós temos essa dificuldade, né? Porque a gente foi construindo, acho que até por isso, acho que a gente tem que desconstruir essa visão pejorativa da cultura africana e construir uma cultura positiva (informação verbal, Adeola, docente negra, entrevista concedida em 2016).

Como aponta Adeola, a instituição na qual realizei a minha pesquisa inúmeras vezes toma como aporte o etnocentrismo cristão europeu, presente no contexto nacional atual, marcadamente influenciado por princípios religiosos. Atualmente vivemos no Brasil um protagonismo do conservadorismo moral religioso dos evangélicos, sobretudo pentecostais, que entraram, mais do que em qualquer outro momento, na disputa pela moralidade pública, para maior controle dos corpos, dos comportamentos e dos vínculos primários. Tal disputa não envolve somente a proteção de suas moralidades, mas também uma luta para que elas sejam inscritas na ordem legal do país (ALMEIDA, 2017) ${ }^{13}$.

Outro aspecto a ser destacado na fala da docente Adeola é o apagamento da cultura africana justificado por um discurso de que tudo que se relaciona aos aportes africanos e afro-brasileiros é algo ruim. Como aponta Araújo (2015), essa reverberação se dá dentro de um quadro de racismo que, sem se descolar dos seus fundamentos ligados ao pertencimento étnico-racial, também atinge todo e qualquer elemento ligado à herança cultural africana no Brasil e às culturas e religiões afro-brasileiras. Indo ao encontro das análises desse antropólogo, Caputo (2009) destaca que o racismo brasileiro é do tipo heterofóbico, ou seja, um racismo que

13 A configuração acima é uma visada da conjuntura atual, que tem sido nominada como onda conservadora. A religião, as religiões e os religiosos fazem parte de um movimento mais amplo, sendo constituintes dele e constituídos por ele. Desse modo, os evangélicos não são "[...] causa e nem resultante, mas [...] estão articulados ao processo social mais geral. Assim como nem todos os evangélicos são conservadores, a pauta conservadora vai além da pauta dos evangélicos conservadores. Dela participam também católicos, outras religiões e não religiosos" (ALMEIDA, 2017, p. 25). 
é a negação absoluta das diferenças, que pressupõe uma avaliação negativa de toda diferença, implicando um ideal explícito ou não de homogeneidade.

E uma das formas desse racismo se manifestar é através da discriminação e do ataque às heranças culturais africanas, sendo que entre os muitos aspectos dessa cultura a religião é o principal alvo dos ataques. Com isso, fica evidente que os casos de intolerância religiosa ligados às religiões afro-brasileiras revelam uma das terríveis faces desse racismo arraigado também na escola, e na vida escolar (ARAÚJO, 2015, p. 56).

Outro elemento a ser destacado na fala de Adeola é a ideia de África reduzida a um continente e ligada somente à expressão religiosa derivada de um processo colonial que homogeneíza as diferenças culturais e padroniza as formas de olhar, conceber e criar novas relações entre saberes africanos e afro-brasileiros. "O continente nos foi apresentado como objeto do discurso da história, sem nunca figurar o papel de sujeito. [...] África fala, canta, dança, sussurra, é rica em expressões que ecoam em cada canto do mundo" (RODRIGUES, 2007, p. 7). Essa forma de concepção é uma das chaves construídas pelo colonialismo, estabelecendo modos únicos de percepção do mundo; "as representações são consideradas apenas como imagens apolíticas a serem analisadas e interpretadas como outras tantas gramáticas intercambiáveis, e julga-se que há um divórcio absoluto entre passado e presente" (SAID, 1995, p. 93).

Os negros e as negras passam a ser, dentro desse quadro, apenas comparações ao universo relativo aos brancos, entendidos enquanto os outros, aqueles que não têm os cabelos no formato considerado bonito pela branquitude, aqueles que não estabelecem de modo eurocêntrico suas relações, construindo dentro desse imaginário a percepção de que "o preto é um escravo a quem se permitiu adotar uma atitude de senhor. O branco é um senhor que permitiu a seus escravos comer na sua mesa" (FANON, 2008, p. 182).

No mesmo sentido desse pensamento, Souza (2017, p. 202) destaca que:

Discursos e práticas docentes monoculturais condizem com tais expectativas sociais, que se opõem ao diálogo, ao questionamento da ordem e à dimensão conflitiva das relações sociais. Diferentes modos de pensar e de agir de diferentes sujeitos são concebidos na perspectiva da igualdade que, no fundo, apaga a diferença quando não aprofunda a compreensão dos contextos sociais e não transforma em conteúdo e prática curricular a dimensão sociocultural presente. 
Imerso nesse contexto, realizei minhas observações ao longo de todo o ano de 2016, numa frequência de dois ou três dias por semana (às vezes, quatro), em períodos alternados (manhã e tarde), participando, interagindo, conversando, praticando as ações do dia a dia, e observando as crianças enquanto brincavam entre elas e as relações que estabeleciam com os adultos e as adultas.

Durante a pesquisa, foi fundamental o contato com as crianças pequenininhas nos diferentes momentos, sendo de extrema importância brincar com elas e escutá-las não somente com os ouvidos, mas com todo o nosso corpo. "Somos sujeitos corpóreos e usamos o nosso corpo como linguagem, como forma de comunicação" (GOMES, 2003, p. 173). O corpo transcende nossos modos de andar, falar e gesticular. Todos esses elementos estão ancorados nesse saber e, assim, presentes no nosso contexto, por meio do movimento da diáspora dos povos que habitavam as diferentes regiões do continente africano (HAMPATE BÂ, 2011).

\section{Inquietações para não finalizar}

As nossas pesquisas são enraizadas em nosso local de fala; a posição social que ocupamos no mundo marca diretamente as nossas interpretações dos dados e das experiências que vivenciamos em campo, pois o percurso de construção dos trabalhos científicos está diretamente interligado à nossa subjetividade.

Tudo o que dizemos é sempre "situado", "posicionado". A partir dessa prerrogativa, este artigo é reflexo também de uma autorreflexão a respeito do meu local de fala dentro da branquitude e de como esse mecanismo está relacionado à masculinidade, tendo sempre como elemento para pensar essas relações a desconstrução do meu olhar enquanto sujeito construído socioculturalmente e possuidor de privilégios, os quais inúmeras vezes não nos permitem perceber os diferentes processos de estratificação causados pela transformação das diferenças em desigualdades.

A brancura na educação infantil cotidianamente reforça a soberania e o privilégio impostos pela colonialidade do saber, propiciando às crianças pequenininhas somente o contato com determinadas histórias, estilos estéticos e experiências afetivas; tudo que destoa ou se distancia minimamente da percepção eurocêntrica branca é eliminado ou cerceado do universo infantil nas creches. Essa é uma forma de educar para as relações étnico-raciais, segundo a qual, a cosmologia de mundo do branco é colocada como a mais legítima a ser 
transmitida, reforçando hierarquias postas durante séculos que desumanizam grande parte da humanidade.

Ao longo da pesquisa, pude observar que a minha brancura influenciava socialmente a construção das relações que estabelecia com os sujeitos da creche em que realizei a etnografia. Muitas vezes, as crianças me mostravam o que representava a minha figura enquanto homem branco dentro daquele ambiente, local naturalizado pela racialização das relações sociais. As crianças pequenininhas me fizeram questionar o meu próprio local enquanto pesquisador que estuda as relações étnico-raciais e é branco; a partir desse movimento, pude compreender as relações por meio de outro prisma e problematizar o meu papel político dentro dessa chave de construção do conhecimento. Nesse sentido, acredito que a branquitude e as culturas infantis devem ser estudadas e aprofundadas em pesquisas futuras no campo da educação infantil, na compreensão tanto do processo de construção da pedagogia da infância quanto das relações estabelecidas criança-criança e adulto-criança.

\section{REFERÊNCIAS}

ALIETTI, Alfredo; PADOVAN. Dario. Sociologia del razzismo. Roma: Coracci editores, 2000.

ALMEIDA, Ronaldo de. A onda quebrada: evangélicos e conservadorismo. Cadernos Pagu, Campinas, n. 50, e175001, 2017. Disponível em: http://www.scielo.br/scielo. php?script=sci_arttext\&pid=S01043332017000200302\&lng=en\&nrm=iso. Acesso em: 13 out. 2018. http://dx.doi.org/10.1590/18094449201700500001

ARAÚJO, Patrício Carneiro. Entre o terreiro e a escola: Lei 10.639/2003 e intolerância religiosa sob o olhar antropológico. 2015. 242 f. Tese (Doutorado em Ciências Sociais) - Pontifícia Universidade Católica de São Paulo, São Paulo, 2015.

BASTIANONI, Paola; VILLANO, Paola. Il bambino e l'incontro con l'altro. In: EMILIANI, Francesca. Il bambini nella vita quotidiana: psicologia sociale della prima infanzia. Roma: Coracci Editore, 2013, p. 221-249.

BENTO, Maria Aparecida Silva. Branqueamento e branquitude no Brasil. In: BENTO, Maria Aparecida Silva; CARONE, Iray. Psicologia social do racismo: estudos sobre branquitude e branqueamento no Brasil. Petrópolis: Vozes, 2002. p. 25-58.

BRAH, Avat. Diferença, diversidade, diferenciação. Cadernos Pagu. Campinas, n. 26, p. 329-376, 2006. 
CAPUTO, Stela Guedes. Ogan, adósu, òjè, ègbónmi e ekedi - O candomblé também está na escola. Mas como? In: BARBOSA, Antônio Fávio; CANDAU, Vera Maria. (Orgs.). Multiculturalismo, diferenças culturais e práticas pedagógicas. Petrópolis: Vozes, 2009, p. 149-181.

CARDOSO, Cintia; DIAS, Lucimar Rosa. A investigação acadêmica sobre processos de branquitude na educação infantil: uma reflexão inicial. In: MULLER, Tânia M. P.; CARDOSO, Lourenço. Branquitude: estudos sobre a identidade branca no Brasil. Curitiba: Appris, 2017. p. 293-309.

CARDOSO, Lourenço C. O branco objeto: o movimento negro situando a branquitude. Instrumento, Juiz de Fora, v. 13, p. 81-93, 2011.

CARNEIRO, Sueli. A construção do outro como não-ser como fundamento do ser. 2005. 340 p. Tese (Doutorado em Educação) - Faculdade de Educação, Universidade de São Paulo, São Paulo, 2005.

CAVALLEIRO, Eliane S. Do silêncio do lar ao silêncio escolar: racismo, preconceito e discriminação na educação infantil. São Paulo: Contexto, 2003.

CORSARO, William. A. Entrada no campo, aceitação e natureza da participação nos estudos etnográficos com crianças pequenas. Educação e Sociedade, Campinas, v. 26, n. 91, p. 443-464, maio/ago. 2005.

. Sociologia da infância. 2. ed. Porto Alegre: Artmed, 2011.

CURCIO, Anna; MELLINO, Miguel. La Razza al Lavoro: Rileggere il razzismo, ripensare l'antirazzismo in Itália. In: CURCIO, Anna; MELLINO, Miguel (Orgs.). La razza al lavoro. Roma: Manifesto Libri, 2012. p. 7-36.

DIAS. Lucimar Rosa. Diversidade Étnico-racial e Educação Infantil. Três Escolas. Uma questão. Muitas Respostas, Dissertação (Mestrado em Educação). UFMS, 1997.

. No fio do horizonte: educadoras da primeira e o combate ao racismo. Tese (Doutorado em Educação) - Faculdade de Educação, Universidade de São Paulo, São Paulo, 2007.

FANON, Frantz. Pele negra, máscaras brancas. Salvador: EDUFBA, 2008.

FARIAS, Ana Carolina Batista de. Loira você fica muito mais bonita: relações entre crianças de uma EMEI da cidade de São Paulo e as representações étnico raciais em seus desenhos. 2016. 157 p. Dissertação (Mestrado em Sociologia da Educação) - Faculdade de Educação, Universidade de São Paulo, São Paulo, 2016.

FERNANDES, Florestan. O negro no mundo dos brancos. 2. ed. São Paulo: Global, 2007. . A integração do negro na sociedade de classe. 2. ed. São Paulo: Global, 2008.

FINCO, Daniela. Faca sem ponta, galinha sem pé, homem com homem, mulher com mulher: relações de gênero nas brincadeiras de meninos e meninas na pré-escola. $184 \mathrm{p}$. Dissertação. (Mestrado) - Faculdade de Educação, Universidade Estadual de Campinas, Campinas, 2004. 
GEERTZ, Clifford. Uma descrição densa: por uma teoria interpretativa da cultura. In: . A interpretação das culturas. Rio de Janeiro: Zahar Editores, 1978. p. 13-41.

GOMES, Nilma L. Educação, identidade negra e formação de professores/as: um olhar sobre o corpo negro e o cabelo crespo. Educação e Pesquisa, São Paulo, v. 29, n. 1, p. 167-182, jan./jun. 2003.

. Relações étnico-raciais, educação e descolonização dos currículos. Currículo sem Fronteiras, v. 12, p. 98-109, 2012.

GOMES, José Ney Costa. Adeus ao eu: a enunciação do outrar-se. Kalíope, São Paulo, ano 1, n. 1, p. 93-109, 2005.

HALL, Stuart. New ethnicities. In: DONALD, James; RATTANSI, Ali (Orgs.). Race, culturs and difference. London: Sage, 1992. p. 252-259.

HAMPATE BÂ, Amadou. A tradição viva. In: KI-ZERBO, Joseph (Org.). História Geral da África, São Paulo: Ática/UNESCO, 2011.

HASENBALG, Carlos. Discriminação e desigualdades raciais no Brasil. 2 ed. Rio de Belo Horizonte: Editora UFMG, Janeiro: IUPERJ, 2005.

LABORNE, Ana Amélia de Paula. Branquitude em foco: análises sobre a construção da identidade branca de intelectuais no Brasil. 2014. 159 f. Tese (Doutorado) - Curso de Doutorado em Educação, Universidade Federal de Minas Gerais, Belo Horizonte, 2014. Disponível em: http://www.bibliotecadigital.ufmg.br/dspace/bitstream/handle/1843/BUOS-9TDHHV/tese_final_revisada_ana_dez.pdf?sequence=1. Acesso em: $03 \mathrm{dez} .2017$.

MAUSS, Marcel. Três observações sobre a sociologia da infância. Pro-Posições [on-line]. v. 21, n. 3, p. 237-244, 2010. Disponível em: http://www.scielo.br/scielo.php?script=sci arttext\&pid=S0103-73072010000300014. Acesso em: 02 set. 2018.

MELLINO, Miguel. La teoria postcoloniale come critica culturale. Tra etnografia della società globale e apologia delle identità “deboli”. Translature [Blog]. 2015. Disponível em: https://translature.files.wordpress.com/2015/03/mellino-2.doc. Acesso em: 02 set. 2018.

MBEMBE, Achille. Crítica da razão negra. Lisboa: Antígona, 2014.

MISKOLCI, Richard. O desejo da nação: masculinidade e branquitude no Brasil de fins do XIX. São Paulo: Annablume, 2012.

MUNANGA, Kabengele. Rediscutindo a Mestiçagem no Brasil: Identidade Nacional versus Identidade Negra. Belo Horizonte: Autêntica, 2004.

OLIVEIRA, Fabiana. Um estudo sobre a creche: o que as práticas educativas produzem e revelam sobre a questão racial? 112 fls. Dissertação (Mestrado em Educação) - Centro de Educação e Ciências Humanas, Universidade Federal de São Carlos (UFSCar). São Carlos, 2004. 
OLIVEIRA, Lúcio Otavio Alves. Expressões de vivencia da dimensão racial de pessoas brancas: representações de branquitude em indivíduos brancos. 135 fls. Dissertação (Mestrado em Psicologia) - Faculdade de Filosofia e Ciências Humanas, Universidade Federal da Bahia (UFBA). Salvador, 2007.

QUIJANO, Anibal. Colonialidade do saber: eurocentrismo e ciências sociais. In: LANDER, Edgardo (Org.). A colonialidade do saber: eurocentrismo e ciências sociais. Perspectivas latino-americanas. Colección Sur Sur, CLACSO, Ciudad Autónoma de Buenos Aires, Argentina, 2005. p. 227-278. Disponível em: http://bibliotecavirtual.clacso.org. ar/ar/libros/ lander/pt/Lander.rtf. Acesso em: 02 nov. 2018.

QUIJANO, Aníbal. Colonialidad del poder y clasificación social. In: CLÍMACO, Danilo Assis (Org.). Cuestiones y horizontes: de la dependencia histórico-estrutural a la colonialidad/descolonialidad del poder. Buenos Aires: CLACSO, 2014.

RIBEIRO, Djamila. O que é lugar de fala? Belo Horizonte: Letramento/Justificando, 2017.

ROCHA, Sandra. A educação como projeto de melhoramento racial: uma análise do art. 138 da Constituição de 1934. Revista Eletrônica de Educação, v. 12, n. 1, p. 61-73, jan./abr. 2018.

ROSEMBERG, Fulvia. Educação infantil, classe, raça e gênero. Cadernos de Pesquisa (Fundação Carlos Chagas), São Paulo, v. 96, pp. 3-86, 1996.

RODRIGUES, Andreia Barreto. Algumas contribuições para um programa de estudos afro-brasileiros. Dissertação (Mestrado) - Centro de Educação e Ciências Humanas, Universidade Federal de São Carlos. São Carlos, 2007.

SAFFIOTI, Heleieth. Gênero, patriarcado, violência. São Paulo: Fundação Perseu Abreu/ Expressão Popular, 2015.

SAID, Edward. Cultura e imperialismo. São Paulo: Companhia das Letras, 1995.

SANTOS, Milton. Metamorfoses do espaço habitado. São Paulo: Hucitec, 1988.

SANTOS, Boaventura Souza. Pela Mão de Alice. São Paulo: Cortez Editora, 1995.

SCHUCMAN, Lia Vaniner. Branquitude à brasileira: hierarquias e deslocamentos entre oriegem, gênero e classe. In: CAHEN, Michel; BRAGA, Ruy. Para Além do pós(-) colonial. São Paulo: Alameda, 2018, p. 167-202.

SEYFERT, Giralda. Eugenia, racismo e o problema da imigração no Brasil. In: Seminário Nacional de Historia da Ciência e Tecnologia, 6., Rio de Janeiro. Anais do Seminário Nacional de Historia da Ciência e Tecnologia, Rio de Janeiro: Sociedade Brasileira de História da Ciência, 1987, p. 248-252.

SOVIK, Liv. Preto no branco: Stuart Hall e a branquitude. In: MULLER, Tânia M. P.; CARDOSO, Lourenço. Branquitude: estudos sobre a identidade branca no Brasil. Curitiba: Appris, 2017. p. 141-154. 
SPIVAK, Gayatri Chakravorty. Pode o subalterno falar? Belo Horizonte: UFMG, 2010.

SOUZA, Ellen Gonzaga de Lima. Percepções de infância de crianças negras por professoras de Educação Infantil. Dissertação (Mestrado em Educação) - Universidade Federal de São Carlos, 2012.

SOUZA, Márcia Lúcia A. Lá na escola (não) tem racismo!: reflexões sobre experiências formativas em educação para as relações étnico-raciais. Revista Ensino Interdisciplinar. Mossoró, v. 3, n. 08, p. 193- 209, 2017.

TAGUIEFF, Pierre-André. Il Razzismo: pregiudizi, teorie, comportamente. Milano: Rafaello Cortina Editore, 1999

TRINIDAD, Cristiane. Identificação étnico-racial na voz de crianças em espaços de educação infantil. 222f. Tese (Doutorado em Psicologia). Pontifícia Universidade Católica de São Paulo. São Paulo, 2011.

VERGUEIRO, Viviane. Por inflexões decoloniais de corpos e identidades de gênero inconformes: uma análise autoetnográfica da cisgeneridade como normatividade. 244 f. Dissertação (Mestrado em Cultura e Sociedade) - Universidade Federal da Bahia. Salvador, 2016.

WERNECK, Jurema. Nossos passos vêem de longe! Movimentos de Mulheres Negras e Estratégias Políticas contra o sexismo e o racismo. Revista da $A B P N$, v. 1, n. 1, marjun de 2010.

Texto recebido em 17 de abril de 2019. Texto aprovado em 07 de julho de 2019. 